\title{
Environmental health literacy and household air pollution-associated symptoms in Kenya: a cross-sectional study
}

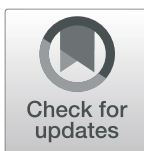

\author{
Jill Raufman ${ }^{1 \dagger}$, Deanna Blansky ${ }^{2 * \dagger}$ D, David W. Lounsbury², Esther Wairimu Mwangi ${ }^{3}$, Qing Lan ${ }^{4}$,
} Jordi Olloquequi ${ }^{5}$ and H. Dean Hosgood III, ${ }^{1,2}$

\begin{abstract}
Background: Household air pollution (HAP) is a significant source of the global burden of disease. Our objective was to evaluate the association between environmental health literacy $(\mathrm{EHL})$, a domain of health literacy $(\mathrm{HL})$ that describes the ability to use environmental health information to reduce health risks, and symptoms associated with HAP.

Methods: We performed a cross-sectional population-based study of 353 households in Kasarani, Kenya. One individual from each household was surveyed using our novel EHL survey tool. Baseline characteristics were compared between individuals who were symptomatic (i.e., experiencing cough, shortness of breath, phlegm production, wheeze, chest tightness, headache, eye irritation, or burns from cooking at least 5 times per month) versus individuals who were asymptomatic (i.e., experiencing none or symptoms no more than once per month). Multivariate logistic regression was used to determine the odds ratios (OR) of self-reported symptoms associated with $\mathrm{HL}$, stratified by median EHL, adjusting for education, self-perceived health and solid fuel use.
\end{abstract}

Results: A total of 100 individuals (28\%) reported experiencing one or more symptoms at least 5 times per month, including $31.2 \%$ of solid fuel users and $30.3 \%$ of non-solid fuel users. Among individuals with high $\mathrm{EHL}$, higher $\mathrm{HL}$ was associated with lower risk of experiencing symptoms $(\mathrm{OR}=0.26 ; 95 \% \mathrm{Cl} 0.10-0.67)$, however, there was no association among individuals with low $\mathrm{EHL}(\mathrm{OR}=0.85 ; 95 \% \mathrm{Cl} 0.34-2.13)$. Among solid fuel users, the association between $\mathrm{HL}$ and risk of experiencing symptoms was driven by individuals with high $\mathrm{EHL}(\mathrm{OR}=0.30 ; 95 \% \mathrm{Cl} 0.05-$ 1.84), rather than those with low $\mathrm{EHL}(\mathrm{OR}=1.22 ; 95 \% \mathrm{Cl} 0.36-4.16)$.

Conclusions: To the best of our knowledge, this was the first study to assess the association between $E H L, H L$, and HAP-associated symptoms. Our findings highlight the potential importance of EHL in promoting sustainable interventions to reduce symptoms associated with HAP from solid fuel use among communities in Kenya.

Keywords: Solid fuel, Household air pollution, Health literacy, Environmental health literacy

\footnotetext{
* Correspondence: blansky@mail.einstein.yu.edu

${ }^{\dagger}$ Jill Raufman and Deanna Blansky contributed equally to this work.

${ }^{2}$ Department of Epidemiology and Population Health, Albert Einstein College

of Medicine, 1300 Morris Park Ave., Bronx, New York 10461, USA

Full list of author information is available at the end of the article
}

(C) The Author(s). 2020 Open Access This article is licensed under a Creative Commons Attribution 4.0 International License, which permits use, sharing, adaptation, distribution and reproduction in any medium or format, as long as you give appropriate credit to the original author(s) and the source, provide a link to the Creative Commons licence, and indicate if changes were made. The images or other third party material in this article are included in the article's Creative Commons licence, unless indicated otherwise in a credit line to the material. If material is not included in the article's Creative Commons licence and your intended use is not permitted by statutory regulation or exceeds the permitted use, you will need to obtain permission directly from the copyright holder. To view a copy of this licence, visit http://creativecommons.org/licenses/by/4.0/ The Creative Commons Public Domain Dedication waiver (http://creativecommons.org/publicdomain/zero/1.0/) applies to the data made available in this article, unless otherwise stated in a credit line to the data. 


\section{Background}

Household air pollution (HAP) attributed to the burning of solid fuels, such as coal, wood, and dung for heating and cooking is a key contributor to ambient air pollution, morbidity, and mortality [1, 2]. Worldwide, HAP ranks among the top 10 risk factors for mortality; among countries considered lower income countries (LIC), it ranks as the second leading mortality risk factor [3]. Approximately 3 billion people are exposed to HAP, contributing to a total of over 4 million deaths per year and more than $50 \%$ of premature deaths due to pneumonia among children under 5. In Kenya, use of solid fuels for cooking account for $95 \%$ of the rural population, $51 \%$ of the urban population, and $84 \%$ of the national total population, leading to approximately 44,000 deaths per year [4].

Persons living in poverty experience the greatest morbidity and mortality attributable to pollution, with deaths due to HAP highly concentrated in the world's poorest countries [5], where health literacy (HL) levels are also among the lowest [6]. Within the past 10 years, advances in the production of cheaper, cleaner, improved cookstoves have served to reduce HAP [7]. However, acceptance and adoption of these improved stoves is challenging [8-10]. Although there have been interventions to reduce exposure via safer cooking practices, build community awareness of HAP danger, alter fuel availability, reduce the cost of cleaner cookstoves, improve the actual environment of the household and villages, and modify patterns of daily living, access to affordable non-solid fuel cookstoves has remained a major barrier to reducing solid fuel use [11].

HL is defined by the Institute of Medicine as "the individuals' capacity to obtain, process and understand basic health information and services needed to make appropriate health decisions" [12]. HL enables one to make informed decisions and to advocate for themselves, their family, and for their community. Persons with lower HL may be less inclined to appreciate the relationship between lifestyle factors and health outcomes, which may suppress constructive health behavior changes [13].

Environmental health literacy (EHL) is a domain of HL that describes the ability to search for, understand, evaluate, and use environmental health information to promote more informed choices and reduce health risks $[14,15]$. In this frame, EHL combines theories from both environmental and health literacy to grow the expertise and knowledge needed to both understand and use information that will lead to behavioral changes. Collective improvements in EHL will hopefully lead to positive health effects for individuals as well as for their families and the environment-at-large.

Despite current and expected increased levels of investment in delivery of cleaner cookstove technologies, current uptake has not proven sufficient for ensuring retained use to yield significant public health benefits. We hypothesize that EHL may be associated with health outcomes attributable to HAP, providing further evidence that EHL may be used to help identify barriers to improved cookstove adoption and improve health outcomes.

\section{Methods}

Subjects were randomly selected from households in the community of Kasarani, outside of Nairobi, Kenya. In total, 360 households were approached and asked to participate. The surveys were translated from English to Swahili by a professional interpreter and administered by community health workers affiliated with St. Francis Community Hospital in Kasarani. Answers were given by the household member who responded. Responses were independently back translated from Swahili to English. Seven individuals refused, which led to a $98 \%$ participation rate $(353 / 360)$.

Data was collected using a questionnaire designed to examine the association between HL, EHL and frequency of HAP-associated symptoms [16]. The questionnaire also asked questions related to demographics and cumulative HAP exposure. A number of survey questions were based on earlier validated non-American health literacy surveys $[17,18]$. Data included: 1) measures of cooking fuel exposure, 2) household income and education level, 3) variables used as proxies to assess HL and EHL levels, and 4) frequency of HAP-associated symptoms (cough, shortness of breath, phlegm production, wheeze, chest tightness, headache, eye irritation, or burns from cooking). HL assessment included questions regarding the degree to which individuals agreed with the following: comprehension and ability to use information received by physicians to make health decisions, find information on treatment options, and take part in activities that improve health within their community. EHL was assessed using questions such as: 1) breathing smoke from the jiko can lead to coughing, 2) pollution can be caused by smoke from the jiko, and 3) I can't do much about it, scored using a 5-point Likert scale. Mean HL and EHL were coded using a 5-point scale, with 5 indicating high HL or EHL, and 1 indicating low. The mean response of 11 questions was included in the calculation of mean $\mathrm{HL}$ and response of 28 questions was used in the calculation of mean EHL.

Composite variables were created to measure mean EHL, exposure, symptoms, and self-reported health. Fuel type was collapsed into a dichotomous (solid vs nonsolid) variable. Non-solid fuels included electricity, liquefied petroleum gas (LPG), biogas, and kerosene. Solid fuels included coal, charcoal, wood, straw, shrubs, agricultural crop, and dung. Mean exposure incorporated 
type of fuel use, frequency of fuel use, and presence of ventilation. Ten questions regarding household exposure were recoded to 1 (high exposure) or 0 (low exposure) then averaged to calculate the mean exposure rate for each individual. Symptom frequency was reported on a scale of 1-5 and included self-reported cough, shortness of breath, productive cough, wheeze, chest tightness, headache, and eye irritation. Individuals were then classified based on symptom frequency. Individuals who experienced one or more symptoms $\geq 5$ times per month were compared to individuals who experienced symptoms once per month or not at all. Education was dichotomized to none/primary versus secondary/college and income was dichotomized at the median value of $3000 \mathrm{KSH}$. Finally, self-reported health was dichotomized to good/very good/excellent versus fair/poor.

Baseline characteristics were compared by symptom status using a two-sample t-test or chi-square test. Frequency of self-reported symptoms were compared between high HAP exposure and low HAP exposure (dichotomized at the mean of 0.51). Univariate logistic regression was used to assess the association between fuel type, mean exposure, EHL, HL, and self-reported health score with frequency of symptoms at least 5 times per month. Univariate models were then stratified by solid versus non-solid fuel use. Multivariate logistic regression was used to assess the association between symptoms at least 5 times per month and HL, adjusting for EHL, self-reported health (good-excellent vs. poorfair), and education level. Given suggestion of an interaction between EHL and HL ( $p$ for interaction $=0.09$ ), we then stratified our model by median EHL. The model was also stratified by fuel type (solid versus non-solid). Given the potential health risk associated with kerosene use, we ran a sensitivity analysis including only kerosene users. All statistical analyses were conducted using STATA version 16.0.

\section{Results}

Among our 353 participants, 28\% reported symptoms at least 5 times per month (Table 1). Symptomatic individuals reported similar average exposure to $\operatorname{HAP}(p=0.41)$ and clean versus solid fuel use $(p=0.89)$. Health was perceived as fair/poor among $51.3 \%$ of symptomatic individuals, compared to $42.3 \%$ of asymptomatic individuals $(p=0.18)$. Mean HL, education and income levels were similar among less symptomatic and symptomatic individuals. Individuals who reported high rates of HAP exposure had higher frequency of headache $(16.3 \%$ versus $9.5 \% ; p=0.06)$, and shortness of breath $(9.8 \%$ versus 4.7\%; $p=0.07$ ) (Fig. 1).

In our univariate models, we found that higher $\mathrm{HL}$ was associated with lower risk of experiencing symptoms among those with high EHL $(\mathrm{OR}=0.53$; 95\% CI $0.28-$
Table 1 Characteristics of Individuals Interviewed in Kasarani, Kenya $(n=353)$

\begin{tabular}{|c|c|c|c|}
\hline Characteristics $^{+}$ & $\begin{array}{l}\text { Symptom } \\
\text { Frequency } \geq 5 \text { per } \\
\text { month }(\boldsymbol{n}=100)\end{array}$ & $\begin{array}{l}\text { Symptom } \\
\text { Frequency }<5 \text { per } \\
\text { month }(\boldsymbol{n}=253)\end{array}$ & $p$-value \\
\hline Cooking fuel use & & & 0.89 \\
\hline Clean fuel & $44(30.3)$ & $101(69.7)$ & \\
\hline Solid fuel & $38(31.2)$ & $84(68.9)$ & \\
\hline Health perception & & & 0.19 \\
\hline $\begin{array}{l}\text { Excellent/very good/ } \\
\text { good }\end{array}$ & 37 (27.6) & $97(72.4)$ & \\
\hline Fair/poor & $39(35.5)$ & $71(64.6)$ & \\
\hline Education level & & & 0.18 \\
\hline None/Primary & $37(25.9)$ & $106(74.1)$ & \\
\hline Secondary/College & $55(32.9)$ & $112(67.1)$ & \\
\hline $\begin{array}{l}\text { Household Income/ } \\
\text { month }\end{array}$ & & & 0.21 \\
\hline KSH 0-3000 & $48(68.8)$ & $106(31.2)$ & \\
\hline KSH 3001-10,000 & $37(24.7)$ & $113(75.3)$ & \\
\hline Exposure score* & $0.53 \pm 0.23$ & $0.51 \pm 0.22$ & 0.41 \\
\hline $\begin{array}{l}\text { Environmental health } \\
\text { literacy score** }\end{array}$ & $3.67 \pm 0.40$ & $3.54 \pm 0.36$ & 0.002 \\
\hline Health literacy score* & $4.39 \pm 0.58$ & $4.48 \pm 0.67$ & 0.28 \\
\hline
\end{tabular}

${ }^{+} \mathrm{N}$ (row \%). Missing data on fuel use $(n=86)$, self-perceived health $(n=109)$, and education $(n=43)$

*Range for composite variables: exposure $0-1$, environmental health literacy $1-5$, health literacy $1-5$. Listed as mean \pm standard deviation

1.01), but not among those with low EHL $(\mathrm{OR}=0.84$; 95\% CI 0.52-1.34). After adjusting for education, EHL, and self-reported health we found that higher HL was associated with lower risk of experiencing symptoms $(\mathrm{OR}=0.46$; 95\% CI 0.25-0.86; Table 2). Among those with high EHL, increasing HL was associated with lower risk of experiencing symptoms $(\mathrm{OR}=0.26$; $95 \% \mathrm{CI} 0.10$ $0.67)$, however, there was no association among individuals with low EHL (OR $=0.85 ; 95 \%$ CI 0.34-2.13). Among solid fuel users, the association between $\mathrm{HL}$ and risk of experiencing symptoms was driven by individuals with high EHL $(\mathrm{OR}=0.30 ; 95 \%$ CI 0.05-1.84), rather than those with low EHL (OR $=1.22$; 95\% CI 0.36-4.16). Similarly, non-solid fuel users with high EHL had lower risk of experiencing symptoms $(\mathrm{OR}=0.22$; $95 \%$ CI $0.06-$ $0.75)$, but not among those with low EHL ( $\mathrm{OR}=0.70$; $95 \%$ CI 0.13-3.90). In our sensitivity analysis of kerosene users, we found that increasing HL was associated with lower risk of experiencing symptoms among individuals with high EHL $(\mathrm{OR}=0.17$; 95\% CI 0.04-0.77), but not among those with low EHL (OR $=0.86$; 95\% CI $0.13-$ 5.45). We found a similar association between $\mathrm{HL}$ and relative risk of daily increase in symptoms $(R R=0.01$, 95\% CI 0.00-0.13). 


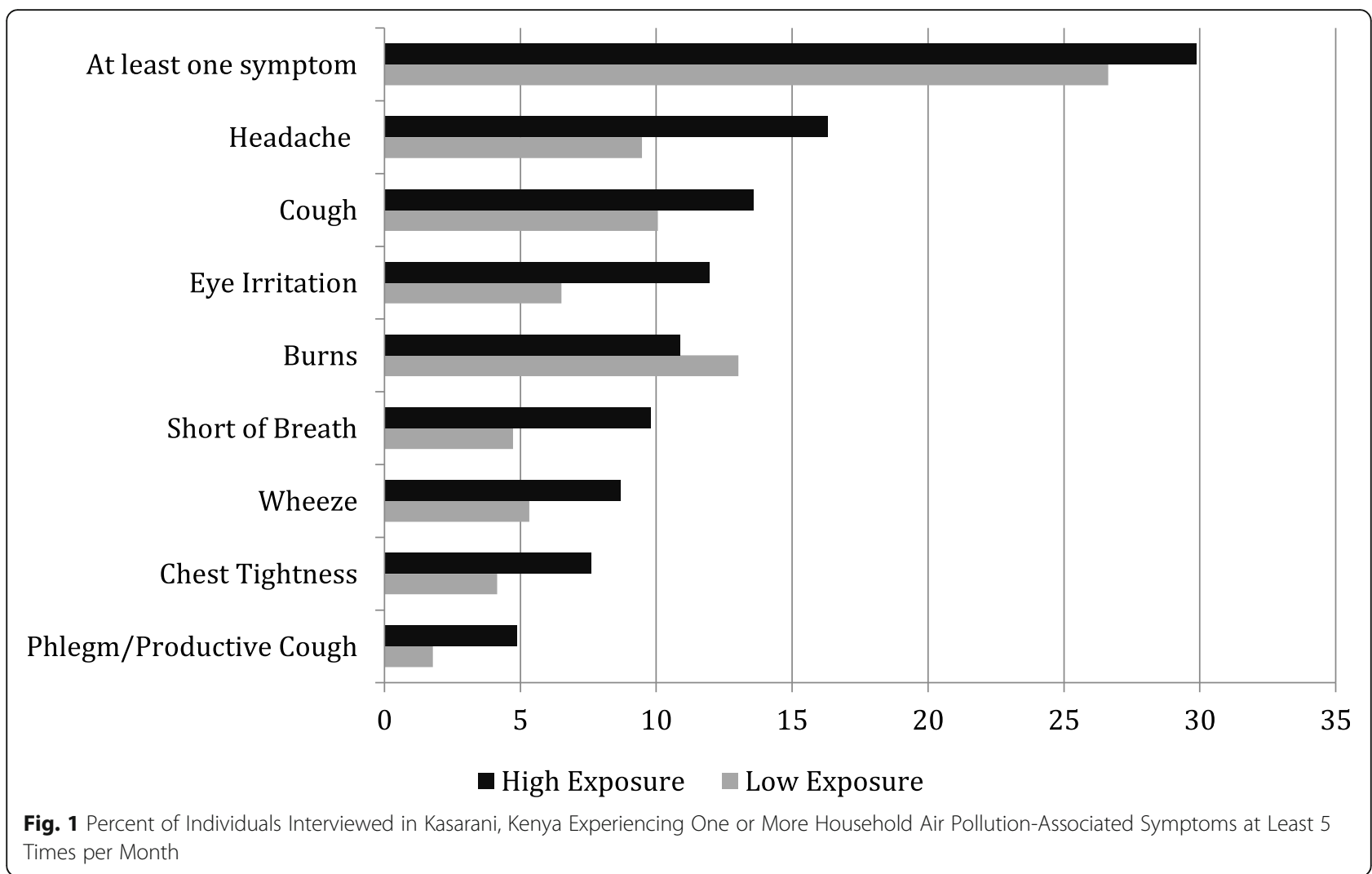

\section{Discussion}

The Lancet Commission on Pollution and Health recommends cleaner fuels and cookstoves at all levels of intervention [5]. A number of studies examining factors preventing uptake of improved cookstove technologies in resource-limited settings have focused on economic and select sociocultural factors, however, resulting interventions providing access to cleaner cookstoves and non-solid fuel have yielded limited to no uptake of clean cookstoves [19]. Our novel results suggest that higher EHL may help improve HAP-associated health outcomes among individuals who use solid fuel stoves. For example, those with an understanding of the role of smoke from the traditional jiko on health may be more likely to utilize proper ventilation or be willing to switch to a clean cookstove.

We conducted a survey designed with an emphasis on $\mathrm{HL}$ and EHL questions administered to an underserved population in East Africa. Although there are validated measures to assess HL levels in high income countries [20], little research has evaluated HL in LMICs, and so there is little information available to evaluate the burden and scope of low HL there [21]. In addition, less is known about EHL and measures have not yet been fully developed. As stated by Ros Dowse, "valid, meaningful data will only be generated if measures reflect local context, culture, and linguistic diversity, accommodate the full range of literacy and cognitive skills, and do not exclude sectors of the population" [22] A number of survey questions, however, were based on earlier validated nonAmerican health literacy surveys $[17,18]$."

In an effort to explore the role of EHL and implementation of clean cookstoves, we performed an exploratory analysis of the association between EHL, symptoms, and willingness to change to a clean cookstove. We found that $95.4 \%$ of individuals experiencing symptoms at least 5 times per month were willing change their stove type, while this was only true of $76.4 \%$ of individuals who experienced fewer symptoms $(p<0.001)$. Given our limited sample of individuals with data on willingness to change stove type among symptomatic solid fuel users, we had limited power to detect an association between EHL and willingness to change stove type $(p=0.06)$. Incorporating EHL into future interventions may be a potential way to address the global burden of HAP in LMICs.

The purpose of EHL is to prevent environmentally induced diseases through intervention and education. It concentrates on addressing the pollution sources and promoting behavior changes to prevent or lessen exposure to pollutants [15]. EHL can be seen as a means that both individuals and groups use for critical reflection within their local socioeconomic setting rather than as a type of HL that integrates specific expertise of environmental factors $[23,24]$. Understanding how levels of HL 
Table 2 Association between Health Literacy, Environmental Health Literacy and Household Air Pollution-Associated Symptoms Greater than Weekly Among Solid and Non-Solid Fuel Users $(n=172)$

\begin{tabular}{|c|c|c|}
\hline Health Literacy* & Odds Ratio & 95\% Confidence Interval \\
\hline \multicolumn{3}{|c|}{ Solid \& Non-Solid Fuel Users $(n=172)$} \\
\hline Solid \& Non-Solid Fuel Users ${ }^{1}$ & 0.46 & $0.25-0.86$ \\
\hline \multicolumn{3}{|l|}{ Environmental Health Literacy ${ }^{2}$} \\
\hline Low & 0.85 & $0.34-2.13$ \\
\hline High & 0.26 & $0.10-0.67$ \\
\hline \multicolumn{3}{|l|}{ Solid Fuel Users $(n=80)$} \\
\hline All Solid Fuel Users ${ }^{3}$ & 0.59 & $0.21-1.64$ \\
\hline \multicolumn{3}{|l|}{ Environmental Health Literacy ${ }^{4}$} \\
\hline Low & 1.22 & $0.36-4.16$ \\
\hline High & 0.30 & $0.05-1.84$ \\
\hline \multicolumn{3}{|l|}{ Non-Solid Fuel Users $(n=92)$} \\
\hline All Non-Solid Fuel Users ${ }^{3}$ & 0.30 & $0.12-0.76$ \\
\hline \multicolumn{3}{|l|}{ Environmental Health Literacy ${ }^{4}$} \\
\hline Low & 0.70 & $0.13-3.90$ \\
\hline High & 0.22 & $0.06-0.75$ \\
\hline
\end{tabular}

*Odds ratios listed for odds of having at least one symptom $\geq 5$ times per month per one unit increase in mean HL. Reference group listed as symptoms $<5$ times per month or asymptomatic

${ }^{1}$ Adjusted for environmental health literacy, self-perceived health score, education, and solid fuel use

${ }^{2}$ Model stratified by environmental health literacy adjusted for self-perceived health score, education, and solid fuel use

${ }^{3}$ Modal stratified by solid fuel use adjusted for environmental health literacy, self-perceived health score, and education

${ }^{4}$ Model stratified by environmental health literacy and solid fuel use adjusted for self-perceived health score and education

and EHL may influence health behaviors regarding use of solid- and non-solid fuels for cooking could inform future design and implementation of effective public health programs to address HAP.

The Clean Cooking Alliance, an initiative hosted by the United Nations Foundation, has distributed more than 115 million clean cookstoves to households since 2010, with a goal of achieving universal access to clean cookstoves by 2030 [25]. The Alliance has identified Kenya as one of eight priority countries for clean cookstove provision [26]. While this significant investment is important for reducing economic barriers, implementation should be paired with sufficient measures to enable uptake and retention. Our results suggest that improving EHL may improve health outcomes among populations during their transition from solid fuel to clean cookstoves.

To the best of our knowledge, this was the first study to assess the association between EHL, HL and HAPassociated health outcomes. By doing so, we provide researchers and other stakeholders with a better understanding of the importance of EHL in HAP-associated health outcomes in order to develop public health solutions to address HAP from solid fuel use. One strength of our study was our participation rate (98\%) which allowed us to enroll a large sample of 353 homes. This success is attributed to our longstanding relationship with the community. Given the limited number of solid fuel users $(n=80)$ and non-solid fuel users $(n=92)$ in our model, however, we may have had insufficient power to detect an association between $\mathrm{HL}$ and symptoms among our solid fuel users and high EHL solid fuel users. Additionally, of the 353 individuals, 42 reported cough, 26 reported shortness of breath, 12 reported phlegm, 25 reported wheeze, 21 reported chest pain, 46 reported headache, 33 reported eye irritation, and 42 reported burns $\geq 5$ times per month. Therefore, we had insufficient sample size to evaluate the association between EHL, HL and individual symptoms. Larger studies are needed to further evaluate the role of EHL, HL and specific symptoms associated with HAP. Additional research is needed to assess the determinants of HL and EHL in Kenya and other LMICs. Future research should also specify the household member who should respond, which would allow the study of HAPassociated health outcomes among individuals across the life course, as well as expansion of our study to other communities in LMICs.

\section{Conclusions}

Our findings suggest the importance of promoting EHL among individuals exposed to HAP to improve health outcomes among communities that continue to use solid fuel in Kenya. Future interventions should consider targeting EHL in an attempt to reduce HAP-associated disease.

\section{Abbreviations}

HAP: household air pollution; LMIC: low- and middle-income country; $\mathrm{HL}$ : health literacy; EHL: environmental health literacy

\section{Acknowledgements}

Not applicable.

\section{Authors' contributions}

$J R$ and HDH designed the study. JR and EWM acquired the data. JR, DB, and $\mathrm{HDH}$ analyzed and interpreted the data, and drafted the manuscript. All authors read and approved the final article.

\section{Funding}

This study was funded, in part, by the Einstein Global Health Center, grant \#3A7292. The funding source was not involved in the study design; in the collection, analysis and interpretation of data; in the writing of the report; and in the decision to submit the article for publication.

\section{Availability of data and materials}

The questionnaire used in the current study is available from the corresponding author on reasonable request using the following weblink: www.einstein.yu.edu/faculty/13783/jill-raufman/

Ethics approval and consent to participate

This project has been reviewed and approved by the Albert Einstein College of Medicine IRB. All subjects consented to participate.

Consent for publication

Not applicable. 


\section{Competing interests}

None declared.

\section{Author details}

'Global Health Center, Albert Einstein College of Medicine, Bronx, NY, USA. ${ }^{2}$ Department of Epidemiology and Population Health, Albert Einstein College of Medicine, 1300 Morris Park Ave., Bronx, New York 10461, USA. ${ }^{3}$ The Aga Khan University, Nairobi, Kenya. ${ }^{4}$ Division of Cancer Epidemiology \& Genetics, National Cancer Institute, National Institutes of Health, Rockville, MD, USA. ${ }^{5}$ Laboratory of Cellular and Molecular Pathology, Instituto de Ciencias Biomedicas, Universidad Autonoma de Chile, Talca, Chile.

Received: 27 March 2020 Accepted: 12 August 2020

Published online: 25 August 2020

\section{References}

1. HMME. Global burden of air pollution. IHME: Boston, MA; 2013.

2. Toroitich M. Modern stove in the kitchen our saviour. Daily Nation. 2017;2: 2017.

3. HEl. State of Global Air 2017. Boston MA: IHME; 20172017.

4. World Health Organization. Climate and health country profile Kenya. Geneva, Switzerland: WHO; 2015

5. Landrigan PJ, Fuller R, Acosta NJR, Adeyi O, Arnold R, Basu N, et al. The lancet commission on pollution and health. Lancet. 2018;391(10119):462512.

6. Kanj MMW. Health literacy. Nairobi: World Health Organization; 2009.

7. Rehfuess E, Organization WH. Fuel for life: household energy and health. 2006

8. Mobarak AM, Dwivedi P, Bailis R, Hildemann L, Miller G. Low demand for nontraditional cookstove technologies. Proc Natl Acad Sci. 2012;109(27): 10815-20.

9. Bielecki C, Wingenbach $\mathrm{G}$. Rethinking improved cookstove diffusion programs: a case study of social perceptions and cooking choices in rural Guatemala. Energy Policy. 2014;66:350-8.

10. Malla T. Household cooking fuel choice and adoption of improved Cookstoves in developing countries: a review. In: Bank W, editor. World Bank policy Researc hWorking paper no 6903. SSRN: SSRN; 2014.

11. Geary CW, Prabawanti C, Aristani C, Utami P, Desa YD. A field assessment of adoption of improved cookstove practices in Yogyakarta, Indonesia: Focus on structural drivers. Fhi360 Available: http://www.fhi360.org/sites/default/ file. 2012.

12. Institute of Medicine. Health literacy: a prescription to end confusion. National Academies Press Washington, DC; 2004.

13. US Department of Health and Human Services, Office of Disease Prevention and Health Promotion. Quick Guide to Health Literacy.

14. Marsili D, Comba P, Castro PD. Environmental health literacy within the Italian Asbestos project: experience in Italy and Latin American contexts. Ann Ist Super Sanita. 2015;51(3):180-2

15. Finn $S, O^{\prime}$ Fallon $L$. The emergence of environmental health literacy-from its roots to its future potential. Environ Health Perspect. 2015.

16. Environmental Health Literacy Coded Questionnaire. www.einstein.yu.edu/ faculty/13783/jill-raufman/.

17. Dodson S, Good S, Osborne R. Health literacy toolkit for low and middleincome countries: a series of information sheets to empower communities and strengthen health systems; 2015.

18. Suka $M$, Odajima $T$, Kasai $M$, Igarashi $A$, Ishikawa $H$, Kusama $M$, et al. The 14item health literacy scale for Japanese adults (HLS-14). Environ Health Prev Med. 2013;18(5):407-15.

19. Jeuland MA, Pattanayak SK. Benefits and costs of improved cookstoves: assessing the implications of variability in health, forest and climate impacts. PLoS One. 2012;7(2):e30338.

20. Nutbeam D. The evolving concept of health literacy. Soc Sci Med. 2008; 67(12):2072-8

21. de Vries McClintock H. IH connect [internet]: APHA IH section. 2017. Available from: https://aphaih.org/2017/08/01/health-literacy-is-educationalattainment-enough/.

22. Dowse $R$. The limitations of current health literacy measures for use in developing countries. J Comm Healthcare. 2016;9(1):4-6.

23. Chinn D. Critical health literacy: a review and critical analysis. Soc Sci Med. 2011;73(1):60-7
24. Sykes S, Wills J, Rowlands G, Popple K. Understanding critical health literacy: a concept analysis. BMC Public Health. 2013;13(1):150.

25. Clean Cooking Alliance. Global Alliance for Clean Cookstoves is Now the Clean Cooking Alliance. 2018

26. Development E. Dynamic market for improved cooking devices in Kenya. Germany: Eschborn; 2012.

\section{Publisher's Note}

Springer Nature remains neutral with regard to jurisdictional claims in published maps and institutional affiliations.
Ready to submit your research? Choose BMC and benefit from:

- fast, convenient online submission

- thorough peer review by experienced researchers in your field

- rapid publication on acceptance

- support for research data, including large and complex data types

- gold Open Access which fosters wider collaboration and increased citations

- maximum visibility for your research: over $100 \mathrm{M}$ website views per year

At $\mathrm{BMC}$, research is always in progress.

Learn more biomedcentral.com/submissions 